BMJ

Cite this as: BMJ 2020;371:m4247 http://dx.doi.org/10.1136/bmj.m4247 Published: 02 November 2020

\section{Covid-19: "There is no alternative," says Johnson, announcing new restrictions for England}

\section{Zosia Kmietowicz}

New national measures to try to stem the rising number of cases of covid-19 in England will come into force on 5 November, as the government conceded that the surge in cases and hospital admissions now threatened to breach NHS capacity.

Several hospitals already have more inpatients with covid-19 than in the spring surge, said Chris Whitty, England's chief medical officer, at a Downing Street press briefing on 31 October to announce the restrictions, which had been widely circulated in the media. By early December hospital admissions will exceed the peak seen in the first wave of the pandemic, with deaths rising to 800 a day by 24 November, modellers have estimated. ${ }^{1}$

Patrick Vallance, the UK's chief scientific adviser, said, "By the beginning of December we will see the level of deaths seen at the peak of the first wave, if nothing is done. That is a grim picture in the absence of action." Hospital bed use would be exceeded on 20 November, as would ventilator capacity, he said.

The prime minister, Boris Johnson, said that no responsible prime minister could ignore the message of the figures.

He said he still believed that the local strategies introduced in various parts of England in the past few months had been the right approach, because "we know the cost of these restrictions, the damage they do, the impact on jobs, and on livelihoods, and on people's mental health. No one wants to be imposing these kinds of measures anywhere."

There were some signs that these measures had paid off, he said, adding, "In this country, alas, as across much of Europe, the virus is spreading even faster than the reasonable worst case scenario of our scientific advisers, whose models ... suggest that unless we act we could see deaths in this country running at several thousand a day."

He said that over-running the NHS would be a "medical and moral disaster beyond the raw loss of life" because "doctors and nurses would be forced to choose which patients to treat, who would live and who would die-and doctors and nurses would be forced to choose between saving covid patients and non-covid patients."

He added that "the sheer weight of covid demand would mean depriving tens of thousands, if not hundreds of thousands, if not millions, of non-covid patients of the care they need."

If covid cases were allowed to rise along the lines projected, "then the risk is that for the first time in our lives the NHS will not be there for us and for our families," he said. "And so now is the time to take action, because there is no alternative."
From 5 November people should stay at home and leave only for work, exercise, medical reasons, and appointments or to shop for food and essentials or care for vulnerable people. Non-essential shops will close, as will leisure and entertainment venues, bars, pubs, and restaurants, although takeaways can continue. Childcare, early years settings, schools, colleges, and universities will all remain open.

Single adult households can still form exclusive support bubbles with one other household, and people who are extremely clinically vulnerable would not be asked to shield, although they are asked to keep contact with others to a minimum.

The measures last until 2 December, when the tiered system would be reintroduced according to local conditions, said Johnson.

He urged people to continue to use the NHS for scans and other appointments as usual.

Johnson said that Christmas would be very different this year, adding, "It is my sincere hope and belief that, by taking tough action now, we can allow families across the country to be together."

Although health leaders welcomed the plans, which need to be approved by parliament, some regretted that action was not taken in September when a two week "circuit breaker" was recommended by the Scientific Advisory Group for Emergencies (SAGE).

Chaand Nagpaul, the BMA's chair of council, called for a clear exit strategy.

"We cannot afford to have a repeat of the first lockdown, which was followed by a rebound surge in infection and by impacts on the nation's mental health, where the economy is made even more fragile and where the NHS and its workers teeter on the verge of collapse because of delays, confusing rules, and guidance that doesn't work," he said.

"This lockdown period must also be used to ensure we develop a fit-for-purpose test and trace programme with the capacity and responsiveness to promptly isolate those with infection, to contain spread. This will need investment in local public health teams and an end to the fragmented outsourcing arrangements that have failed to deliver, at scandalous cost."

\section{Measures across the UK}

Scotland unveiled five tiers (o to 4 ) of restrictions on 29 October that came into force on 2 November. Level 3 areas include Glasgow, Edinburgh, East Lothian, West Lothian, Falkirk, Stirling, and Dundee. In these areas much of the hospitality sector closed completely (though some restaurants remain open), people have been told to make only essential journeys, and some senior school pupils have to wear face coverings in classrooms as well as in communal areas. 
Wales introduced a 19 day "fire breaker" on 23 September that ends on 9 November, after which people will be asked to take responsibility for keeping levels of the virus down.

Northern Ireland has had restrictions in place since 16 October that ban households from mixing except for essential services, although up to six people can meet in gardens. Two households can form a bubble, and a maximum of 10 people can meet indoors, although overnight stays are banned. Schools reopened on 2 November after closing on 19 October. Half of the region's schools have recorded cases of covid-19.

1 Mahase E. Covid-19: UK government must "get its act together" as modelling suggests 85000 deaths in second wave, experts say. BMJ2020;371:m4242.

doi: 10.1136/bmi.m4242 pmid. 33127605

This article is made freely available for use in accordance with BMJ's website terms and conditions for the duration of the covid-19 pandemic or until otherwise determined by BMJ. You may use, download and print the article for any lawful, non-commercial purpose (including text and data mining) provided that all copyright notices and trade marks are retained. 